\title{
O PARLAMENTO DO MERCOSUL E A CIDADANIA SUL-AMERICANA ${ }^{1}$
}

\author{
Jamile Lourdes Ferreira Tajra ${ }^{2}$ \\ Mônica Dias Martins ${ }^{3}$
}

\begin{abstract}
Resumo
O artigo aborda o papel do Parlamento do MERCOSUL (Parlasul) na construção da cidadania sulamericana. Idealizado para cumprir as funções de "representação cidadã" e harmonizar as legislações dos Estados-membros, o Parlasul trouxe para o centro do debate sobre a integração regional o envolvimento do cidadão nesse processo. $\mathrm{O}$ texto está dividido em quatro tópicos. $\mathrm{Na}$ introdução, delimitamos o objeto e os procedimentos teóricos e metodológicos utilizados. A seguir, apresentamos um histórico das iniciativas de integração regional e a trajetória do MERCOSUL, perpassando seu caráter inicial, marcadamente comercial, até o momento em que os aspectos políticos, sociais e culturais da integração passaram a ter destaque nos acordos firmados pelos governantes do bloco. Por fim, com base no exame de documentos oficiais, analisamos as funções e atividades do Parlasul, buscando verificar os principais temas discutidos pelos parlamentares e os desafios postos ao seu compromisso institucional de fomentar a cidadania no âmbito do MERCOSUL.
\end{abstract}

Palavras-chave: Regionalismo. Integração. América do Sul. Parlamento do MERCOSUL. Cidadania sul-americana.

\begin{abstract}
The article discusses the role of MERCOSUR Parliament (Parlasur) in the making of South American citizenship. Designed to fulfill the functions of "citizen representation" and to harmonize Member States' legislations, Parlasur brought to the center of the debate on regional integration the citizens' involvement in this process. The text is divided into four topics. In the introduction, we delineate the object and the theoretic-methodological procedures. Next, we present a historical view of regional integration initiatives and the trajectory of the MERCOSUR, bypassing its initial character, markedly commercial, until the moment when political, social and cultural aspects of integration became highlighted in the agreements signed by the leaders of the block. Finally, based on the review of official documents, we analyze Parlasur functions and activities, seeking to examine the main issues discussed by its representatives and the challenges posed to its institutional commitment to promote citizenship within MERCOSUR.
\end{abstract}

Keywords: Regionalism. Integration. South America. The MERCOSUR Parliament. South American citizenship.

\section{Resumen}

El artículo analiza el papel del Parlamento del MERCOSUR (Parlasur) en la construcción de la ciudadanía sudamericana. Diseñado para cumplir las funciones de "representación ciudadana" y armonizar las legislaciones de los Estados miembros, el Parlasur trajo al centro del debate sobre el compromiso regional de integración ciudadana en este proceso. El texto se divide en cuatro temas. En la introducción, delimitamos el objeto y los procedimientos teóricos y metodológicos utilizados. En el siguiente momento, hacemos una historia de las iniciativas de integración regional y la trayectoria del MERCOSUR, pasando su carácter inicial, marcadamente comercial, hasta el tiempo en que los aspectos políticos, sociales y culturales de la integración se han dado prominencia en los acuerdos firmados por los gobernantes del bloque. Por fin, con base en el examen de los

${ }^{1}$ DOI deste artigo: http://dx.doi.org/10.5380/recp.v5i2.35733

2 Doutoranda em Ciência Política pela Universidade Federal do Rio Grande do Sul - UFRGS Grupo de Pesquisa Processos Participativos na Gestão Pública/Observatório das Nacionalidades.

3 Professora da Universidade Estadual do Ceará - UECE/Coordenadora do Observatório das Nacionalidades. 
documentos oficiales, analizamos las funciones y actividades Parlasur, tratando de verificar los principales temas tratados por los parlamentarios y los retos que plantea a su compromiso institucional de fomentar la ciudadanía dentro del MERCOSUR.

Palabras Clave: Regionalismo; Integración; América del Sur; Parlamento del Mercosur; Ciudadanía sudamericana.

\section{INTRODUÇÃO}

A instituição de um órgão democrático no MERCOSUL foi uma iniciativa dos líderes executivos dos dois maiores países do bloco. Argentina e Brasil, com vistas a dar maior legitimidade ao processo de integração, por meio do reconhecimento político da sociedade, apresentaram na ocasião de um encontro entre os dois então presidentes, Nestor Kirchner e Lula da Silva, em Brasília, em junho de 2003, uma proposta de criação de um Parlamento regional. A decisão que assumia o interesse comum de estabelecer um Parlamento para o MERCOSUL foi assinada em 06 de outubro de $2003^{4}$ e constou como resultado de uma articulação entre a Comissão Parlamentar Conjunta (CPC) e o Conselho do Mercado Comum (CMC) órgão decisório superior do MERCOSUL.

O Parlasul foi instituído em 2005 em substituição à CPC, sendo inserido na estrutura institucional do bloco no intuito de funcionar como órgão de representação dos povos no âmbito da integração sul-americana. Iniciando suas atividades em 2007, a instituição do órgão inaugurou uma agenda política que, pela primeira vez, admitia a possibilidade do exercício de uma cidadania regional e da integração dos povos da região (FIER, 2008:s/n). A proposta de um Parlamento regional idealizava a participação civil direta no processo de integração, já que sua estabilidade e legitimação se apresentavam como condição sine qua non do reconhecimento dos entes que o integram, em última instância, os cidadãos de cada Estado membro.

O presente artigo aborda o órgão regional e seu compromisso institucional de fomentar a cidadania no interior dos países que compõem o MERCOSUL. O texto apresenta reflexões sobre a integração sul-americana levada a cabo pelo MERCOSUL e, especificamente sobre o Parlasul, em sua primeira fase de institucionalização, entre janeiro de 2007 e dezembro de 2010. Assim, todos os dados apresentados no tocante à atividade do órgão, têm como limite esse horizonte temporal.

O texto está dividido em quatro tópicos, nos quais desenvolve-se o argumento central de que a integração política e social no âmbito do MERCOSUL responde a uma

\footnotetext{
${ }^{4}$ Decisão NO. 26/2003, do CMC.
} 
premissa que se tornou cara à política externa do Brasil nos últimos anos, a aproximação e o alinhamento com os países da América do Sul. Nesse contexto, o fomento aos demais pilares da integração, quais sejam, político, social e cultural, ademais do econômico, ainda que com dificuldades, já em andamento, consta como pedra de toque do processo em questão.

Segundo Pia Riggirozzi (2011), observando em perspectiva histórica, podemos estabelecer uma diferenciação entre as tendências dos processos de integração na América Latina, os quais no atual contexto geopolítico se sobrepõem. Em primeiro lugar existem os projetos com clara ênfase aos fatores comerciais, em que a integração aparece como mecanismo de inserção no mercado global; em segundo, os projetos que, embora se pautem pelo fator comercial, contemplam também plataformas de inflexão, política, social e cultural e; por último, identifica-se um novo regionalismo, em que os fatores políticos e sociais se sobressaem e os países envolvidos passam a assumir o compromisso com o desenvolvimento social por meio de iniciativas radicais com relação à condução de seus recursos econômicos, autoproclamando-se como projetos de "regionalismo transformador" (RIGGIROZZI, 2011:295-6).

Seguindo essa abordagem, assume-se aqui a perspectiva teórica de que o MERCOSUL se insere em um processo, segundo o qual, o regionalismo, transcendendo o caráter comercial, se tornou um "proyecto de autonomia y desarrollo humano que va más allá de la gobernancia nacional, creando instituciones geopolíticas autónomas y promovendo nuevas redes de solidadriedad transnacional” (RIGGIROZZI, 2011:294) em que se ensaiaram novas urgências quanto ao desenvolvimento de outros campos, como o político, o social e o cultural, em que "la búsqueda de proyectos de integración han convertido en un intento real, más allá de cálculos personalistas de corto plazo, y más allá de retóricas y simbolismos políticos". (Ibid:293).

Ainda de acordo com Riggirozzi, o MERCOSUL se insere na segunda perspectiva, segundo a qual, o regionalismo, transcendendo o caráter comercial, apresentou uma clara mudança na estrutura institucional, que passou a dar lugar a órgãos de absorção dos temas sociais agora tomados como prioridade para o sucesso do processo de integração, inaugurando uma terceira fase, que a autora denomina "novo regionalismo", em que se ensaiaram novas urgências quanto ao desenvolvimento de outros campos, como o político, o social e o cultural. 
Por sua vez, enquanto categoria de análise, a expressão cidadania sul-americana não apresenta parâmetros teóricos na literatura. Um rápido levantamento da produção acadêmica mostra que a expressão está vinculada a um constructo institucional, vinculado a um arranjo de integração regional, no caso o MERCOSUL e, mais especificamente, o seu Estatuto da Cidadania (2010).

\section{DA HOSTILIDADE À INTEGRAÇÃO ECONÔMICA}

É certo que o histórico da integração regional apresenta episódios nos quais a junção de forças se dava justamente no intuito de conseguir o apoio político e econômico dos EUA, "em primeiro lugar por necessidades econômicas enfrentadas pelas maiores economias da região e, em segundo, pelos diversos reveses sofridos por seus governantes na busca de apoio norte-americano ao desenvolvimento" (VIDIGAL, 2011:63). As parcerias regionais se dariam pela conformação do interesse comum de levar a cabo os projetos de desenvolvimento nacionais e, via de regra, não absorviam as históricas assimetrias entre os países da região.

A aceitação do Brasil em assumir uma postura de entendimento e coordenação política especificamente com os vizinhos sul-americanos, por sua vez, e ainda que muitas vezes restrita ao discurso diplomático, remonta à década de 1950. Antes disso, o que se percebia era um claro distanciamento do país em relação aos demais países do subcontinente. Como lembra Tiago Fernandes, “em nossa herança colonial, o oceano se torna um rio de fácil navegação, enquanto a bacia do Prata e, especialmente, os Andes e a Amazônia se apresentam como obstáculos naturais intransponíveis" (FERNANDES, 2008:213).

Porém, fixar-se somente no argumento dos obstáculos naturais é assumir o risco de incorrer no erro de ignorar as principais causas do tácito destanciamento do Império brasileiro em relação às Repúblicas Americanas, já que, essa diferenciação em relação aos vizinhos hispânicos, inclusive, "foi uma mistificação instrumental para a construção de uma identidade e de uma ideia de pátria comum e, mais tarde, do sentimento de nacionalidade brasileira" (SANTOS, 2012:17), assim, contribuindo de forma decisiva na definição da nossa identidade.

Dessa forma, o que se percebia praticamente até a metade do século XIX por parte do Império era uma recusa tácita em estabelecer qualquer envolvimento político com os demais países do continente. "O Brasil, monarquia cercada de repúblicas, via seus 
vizinhos com desconfiança” (SANTOS, 2005:29) e a própria escolha pela manutenção da ordem imperial e a não adesão à forma republicana, como fizeram os vizinhos, foi também uma forma de discernir o Brasil, herdeiro de uma civilidade e ordem política europeia, dos vizinhos republicanos "caudilhescos".

Foi com esta postura hostil que o Império pautadamente se posicionou na maior parte de seus sessenta e sete anos. Ainda segundo Santos, a região, apreciada nos relatórios do Ministério das Relações Exteriores do Brasil, RMRE, era até então, um conceito ainda esvaziado de significado e, geralmente, sem correlação pragmática com a realidade. A expressão "América do Sul”, dessa forma,

com a afirmação do conceito de América Latina (inventado em 1850, mas só consolidado completamente após 1945), passou a definir uma entidade geográfica que inclui os doze países americanos ao Sul da República do Panamá (exclusive) e a Guiana Francesa (SANTOS, 2005:200).

$\mathrm{Na}$ dinâmica do desenvolvimento dos mercados capitalistas durante o século XX, as iniciativas de integração regional se deram, sobremaneira, como união entre os países no intuito de fazer frente aos mercados globais, fomentando mecanismos para tornar a região competitiva em relação aos demais mercados globais (DORATIOTO, 1998).

Certamente, novas posturas políticas assumidas, conformam no estabelecimento de novos eixos estratégicos para a integração regional. No entanto, é necessário ter em mente que

lejos de una nueva gran "metanarrativa" de transformación y ruptura, el regionalismo em América Latina refleja, certamente aun parciales, de cambio que combinan una revisión de las políticas del passado con nuevas motivaciones y multifacéticas iniciativas, esto es, políticas sociales, institucionais, económicas y culturales (RIGGIROZZI, 2011:287).

Por conseguinte, ainda de acordo com Riggirozzi, "seria erróneo suponer que la transición de la regionalización comercial a una robustamente centrada em la cooperación política y social constituye una ruptura com el passado reciente em América Latina" (RIGGIROZZI, 2011:286). Na realidade, os esforços de integração regional empreendidos durante o século XX se desenvolveram em larga escala como uma tentativa de superação das dificuldades econômicas que, de forma geral, atingiram o continente no momento 
imediatamente posterior a II Grande Guerra ${ }^{5}$. Assim, entre nós, “a integración regional ha sido principalmente concebida como un instrumento para equilibrar fuentes $\mathrm{o}$ manifestaciones de infuencia externa; esto es la hegemonia de EEUU, la competitividad económica de la UE, el capital internacional y la globalización neoliberal. (Ibid:288).

Em 1941, aproveitando a tendência de parceria comercial e complementaridade de seus sistemas industriais, os ministros das Relações Exteriores da Argentina e do Brasil, firmaram um acordo que visava impulsionar as relações de comércio, demonstrando o propósito comum de no futuro estabelecer um regime de intercâmbio livre, que permitisse no futuro chegar a uma união aduaneira aberta à adesão dos países limítrofes (MONIZ BANDEIRA, 1998:313). Essa iniciativa, porém, foi abandonada devido aos envolvimentos dos dois países nos episódios da II Guerra Mundial, em que o Brasil demonstrou-se fiel aos aliados, unindo-se aos EUA, e a Argentina, por razões comerciais de aproximação da GrãBretanha e afastamento dos EUA, permaneceu neutra.

A Operação Pan-Americana, OPA, de junho de 1958, por sua vez, pode ser definida como a primeira iniciativa brasileira feita com base em "um estado de consciência verdadeiramente latino-americano" (RMRE, 1958, p. 3, apud SANTOS, 2005:196). Projeto de política externa do governo Juscelino Kubitschek, a OPA surgia do contexto mundial pós-II Guerra como tentativa de contenção da extrema pobreza e do subdesenvolvimento em prol do desenvolvimento nacional dos países da região, o que se daria por meio do financiamento norte-americano em troca de uma espécie de "blindagem anticomunista" da América Latina (BUENO, 2011). O plano de fundo da política internacional era, pois, o conflito expresso na polaridade EUA-União Soviética.

\footnotetext{
${ }^{5}$ É necessário destacar, entretanto, que mesmo antes da II Guerra e dos problemas econômicos advindos do conflito, projetos de integração já se ensaiavam na região. Desta maneira, a iniciativa de integração entre Argentina, Brasil e Chile (conhecida como triângulo ABC), cujo esboço de projeto se deu ainda na primeira década do século XX, em 1907, apresenta-se com ponto de partida factual para uma reconstrução histórica da integração sul-americana. Destinado a estabelecer e fomentar a harmonia entre os contratantes, que tratariam de proceder sempre de comum acordo em questões relativas aos seus interesses e aspirações, o $A B C$ vislumbrava assegurar a paz e estimular o progresso na região. Em seus termos, desde que não envolvessem questões de interesses vitais, como a independência, a soberania ou a honra dos contratantes, seria mantido o compromisso mútuo entre os partícipes de preservar a paz e trabalhar para o desenvolvimento da região (BUENO, 2011). Na verdade, o que estava em jogo naquele momento, a despeito de qualquer solidariedade entre os três países, era o interesse comum na garantia do equilíbrio do poder na região. Argentina, Brasil e Chile funcionavam, então, como uma balança de poder cujo desequilíbrio nas relações entre quaisquer desses três países acarretaria numa drástica mudança no cenário e, por conseguinte, no desenvolvimento da região como um todo (MONIZ BANDEIRA, 1998). O projeto ABC demonstra que já no início do século XX havia uma preocupação com acerca de uma concertação entre os países do cone sul por meio da manutenção da ordem e da estabilidade das relações político-diplomáticas entre os países envolvidos. No entanto, como reitera Clodoaldo Bueno (Op.Cit.), mesmo na concepção do Barão do Rio Branco , no projeto ABC "nada constava a respeito de economia e comércio entre as nações envolvidas, não incluía equivalência naval no Cone Sul, a qual veemente descartava, e reafirmava que a aproximação Argentina-Brasil-Chile não se destinava a contrabalançar a influência norte-americana” (BUENO, 2011:46). Não estávamos, pois, nem geográfica nem politicamente nos referindo à América do Sul.
} 
Entretanto, ainda que a OPA tomasse como ponto de partida um "estado de consciência latino-americano", o objetivo do Brasil era claramente o de recuperar o prestígio perdido junto aos EUA, deixando o entendimento regional em segundo plano. Dessa forma, foi a falta de resultados práticos que relegou a Operação ao ostracismo em que caíram as anteriores iniciativas de integração.

Independente do êxito ou fracasso das experiências de integração ensaiadas no subcontinente, a América do Sul como unidade (ou projeto de unidade) não era o horizonte dos acordos firmados até então. De acordo com Carlos Eduardo Vidigal (2011), a América do Sul propriamente dita somente viria a ser vislumbrada como horizonte das intenções políticas do Brasil, a partir do início da década de 1960. Nesse sentido, o Encontro de Uruguaiana, em abril de 1961, entre o presidente argentino, Arturo Frondizi, e brasileiro, Jânio Quadros, simbolizou o ponto alto da dimensão sul-americana da autodeterminada Política Externa Independente, assumida por Quadros e seu chanceler, Afonso Arinos de Melo Franco.

Como sugere ainda Vidigal, pode-se considerar o Encontro de Uruguaiana como o primeiro episódio em que, de forma consistente, a América do Sul era vislumbrada como horizonte de concertação. Tratava-se ali, do "primeiro momento no qual ensaiou-se o estabelecimento de um sistema de consultas recíprocas, vislumbrando-se se a integração econômica em sentido amplo (VIDIGAL, Ibid.:65). Assim, quando o presidente Frondizi propôs que, "para cada unidade monetária que a Argentina despendesse para comprar um novo produto manufaturado brasileiro, a mesma unidade monetária deveria ser gasta pelo Brasil na aquisição de manufaturados argentinos" (VIDIGAL, Ibid.:76), se colocavam de forma inédita os parâmetros que trinta anos depois viriam a ser consagrados no Tratado de Assunção.

Nesse sentido, ainda que nenhuma grande iniciativa da política externa brasileira, e nenhum acordo significativo tenha sido firmado entre os países da região, em parte devido a uma reorientação norteamericanista dada à política exterior argentina pelo novo presidente, José María Guido, nos anos posteriores ao Encontro, é notório que "o horizonte de Uruguaiana era a integração sul-americana e, nesse aspecto, a iniciativa foi pioneira" (VIDIGAL, Ibid.:68).

Nos anos seguintes, destaque-se o Tratado de Cooperação Amazônica, firmado em junho de 1978 entre oito países, que, aos moldes dos acordos na região do Rio da Prata, que envolvendo Argentina e Paraguai, tentou estabelecer parâmetros para o 
desenvolvimento integrado da Bacia Amazônica e o Acordo Tripartite, de outubro de 1979, que pôs fim às divergências entre Argentina, Brasil e Paraguai com relação à Itaipu. À Bacia Amazônica somava-se, então, a Bacia do Rio da Prata na definição dos eixos de integração.

Entre 1960 e 1980, com exceção da assinatura do Tratado de Montevidéu, em 1980, que estabeleceu a Associação Latino-Americana de Integração, ALADI, em substituição à Associação Latino-Americana de Livre Comércio, ALALC, nenhum grande acordo seria firmado em nível regional. De modo geral, a principal inovação da ALADI em relação à ALALC se deu pelo pragmatismo daquela, que passou a aceitar as assimetrias entre os países e a superação destas como requisito essencial a uma eficaz integração econômica.

A partir da segunda metade da década de 1980, com os coincidentes contextos nacionais de reestruturação política, redemocratização e afinidades quanto às políticas exteriores de Argentina e Brasil, se pôde observar a aproximação bilateral que permitiu articulações políticas propensas a um projeto comum de crescimento e desenvolvimento para a região. Foi a Declaração de Iguaçu, de 30 de novembro de 1985, assinada pelos presidentes Raul Alfonsín, da Argentina e José Sarney, do Brasil, que selou a inauguração de um novo episódio nas relações bilaterais entre os dois países.

Nesse sentido, o avanço dos processos de redemocratização, de maneira abrupta na Argentina e
gradual no Brasil, gerou alguns descompassos no diálogo bilateral, mas não prejudicou
o acumulado histórico bilateral, base para a integração iniciada em Foz do Iguaçu [...],
cujo principal resultado foi a criação do Mercosul (VIDIGAL, op.cit.:77).

Alfonsín e Sarney, portanto, começaram a construir as bases para um entendimento real. Naquele contexto, "ambos se deram conta de que sua oportunidade de legitimação histórica estava mais na cooperação mútua, livre dos limites de um jogo interno no qual, além da pouca força política, os dois eram vítimas de uma inflação crônica e interminável” (AZAMBUJA, 2011:82-3).

Assim, com a assinatura da Ata para a Integração Argentino-Brasileira, em 1986, os governantes se propuseram a cumprir o Programa de Integração e Cooperação Econômica (PICE), que definiu as normas para o comércio recíproco e a integração de setores específicos entre os dois países. Mais tarde, em 1988, a assinatura do Tratado de Integração Cooperação e Desenvolvimento, impulsionado principalmente pelo crescimento do comércio bilateral, estabelecia o prazo de dez anos para o estabelecimento definitivo de uma zona econômica comum entre os países.

Dois anos depois, a Ata de Buenos Aires, assinada pelos presidentes Fernando Collor de Melo, do Brasil, e Carlos Saúl Menem, da Argentina, apresentou o projeto de um 
Mercado Comum e, com isso, estabeleceu a pedra fundamental para que se vislumbrasse o projeto maior de integração regional que, no ano seguinte, culminou na criação do MERCOSUL. Desta feita, no ano seguinte, o Tratado de Assunção finalmente viria a afirmar tal pretensão por meio do estabelecimento do tratado, ao qual se uniram Paraguai e Uruguai, estabelecendo o molde inicial do MERCOSUL.

O bloco, em seu molde inicial, encerraria um bloco econômico no formato de Mercado Comum, ou seja, previa a total derrubada das tarifas de exportação para o comércio entre seus membros. ${ }^{6} \mathrm{~A}$ conjuntura à época, entretanto, indica que os objetivos diziam respeito também à consolidação da democracia na região e à superação de uma rivalidade econômica, e até militar, entre Argentina e Brasil.

Para a política exterior do Brasil, o bloco "constitui um projeto político que a crise do neoliberalismo e a permanência de assimetrias tornaram mais flexível, [...] enquanto a diplomacia o percebe como instrumento de reforço do poder de barganha internacional" (BUENO; CERVO, 2011:550). Do ponto de vista de sua estrutura institucional, por sua vez, em consonância com a Constituição brasileira, desde Assunção, se previu o estabelecimento de órgãos voltados ao entendimento político, social e cultural entre os países envolvidos.

Tudo somado, como apresentam Bueno e Cervo (2011:550),

a integração destina-se a criar o polo regional com que melhor se possa realizar metas do multilateralismo da reciprocidade e da globalização da economia brasileira. No fundo, como em todos os países e quadrantes das relações internacionais, a hegemonia do nacional se impõe, mais no século XXI do que nos anos 1990.

\section{DA INTEGRAÇÃO ECONÔMICA À INTEGRAÇÃO CIDADÃ}

Ainda que desde a sua fundação se previsse a integração em múltiplos níveis (econômico, político, social e cultural como os principais deles), nos primeiros anos após a assinatura do Tratado de Assunção, o que se percebeu foi um claro avanço no campo comercial, sobretudo no comércio entre Argentina e Brasil, que cresceu em vertigionosamente com relação ao período anterior a assinatura do tratado, sendo o MERCOSUL, ainda assim, relegado ao plano secundário de inserção internacional do

\footnotetext{
${ }^{6}$ O Tratado de Assunção estabeleceu o prazo de 31 de dezembro de 1994 para a superação desta primeira etapa de integração e a consequente implantação do Mercado Comum, que, diga-se, até hoje não foi integralmente implementado.
} 
Brasil, que preferiu manter múltiplas frentes de ação internacional (relações bilaterais com os EUA, União Europeia, por exemplo).

As diretrizes da política externa do governo Fernando Henrique Cardoso (19952002), embora tenham estabelecido como múltiplos os eixos de atuação dentre os quais a América do Sul, ainda que também presente, não ganhasse protagonismo frente à dileção pelas relações com EUA e países europeus, não deixaram de apresentar importantes bases, não apenas quanto às inclinações políticas, mas também ao conteúdo institucional do bloco.

Assim,

por iniciativa pessoal do presidente Fernando Henrique Cardoso, com base em seu projeto de desenvolvimento regional para o Brasil a partir dos eixos de desenvolvimento concertados no programa "Avança Brasil", foram realizadas as duas primeiras Reuniões de presidentes da América do Sul. [...] Com as Cúpulas de Brasília (2000) e Guayaquil (2002), a definição de "América do Sul" na retórica diplomática brasileira adquiriu, finalmente, contornos definidos - englobando as doze nações (e só estas), que foram convidadas para participar dos dois encontros, ainda que tenha havido observadores de outros países (SANTOS, 2005:201).

Essa iniciativa do governo de FHC, mesmo que não tenha se dado no âmbito exclusivo do MERCOSUL, já que reuniu os presidentes de todos os países da região, simbolizou um ponto de transição entre a velha e a nova fase das relações diplomáticas do Brasil com os demais países sul-americanos.

A partir de 2002, a emergência de líderes de orientação esquerdista nos quatro países integrantes do MERCOSUL inaugurou um momento favorável ao desenvolvimento de todas as instâncias da integração sul-americana. No tocante ao MERCOSUL, a estrutura institucional do bloco passou então a acolher a possibilidade de absorção de organismos para a conformação dos parâmetros políticos e sociais até então ausentes nas iniciativas no âmbito do bloco.

Já a partir de 2003, o presidente Luis Inácio Lula da Silva (2003-2010) estabeleceria desde os primeiros momentos, como prioridade da política externa brasileira o aprofundamento das relações com os países sul-americanos. Já em seu discurso de posse, a 
primeiro de janeiro, o novo presidente ratificava a condução que seu governo pretendia dar a integração regional ${ }^{7}$.

Dali por diante, "o ponto de partida para uma nova inserção do Brasil no cenário internacional [seria] a América do Sul - consolidada a partir da reconstrução do Mercosul, das negociações com a Comunidade Andina e da incorporação do Chile, da Guiana e do Suriname no esforço de integração" (SANTOS, 2005:202).

A criação da Comunidade Sul-Americana de Nações, CASA, em dezembro de 2004, demonstra

mais do que a "circunstância do Brasil", a América do Sul [tornava-se] a referência para a inserção brasileira no mundo do século que se abre. Ultrapassa a etapa a etapa das Reuniões de presidentes da América do Sul, os processos de integração da região ganharam uma nova institucionalidade, desde a perspectiva integradora dos esforços sub-regionais trazida pela criação da CASA (Ibid.:203).

Dessa forma, fugindo à trajetória traçada nos primeiros anos após sua instituição marcados por um caráter essencialmente comercial -, o arcabouço institucional do MERCOSUL passou a absorver a possibilidade de criação e institucionalização de órgãos que promovessem a integração das instâncias política e social, não mais somente das econômica e comercial já - ainda que com dificuldades - encaminhadas.

O primeiro órgão social do bloco, o Foro Consultivo Econômico e Social (FCES), composto por representantes dos setores sindical e empresarial, foi instituído já pelo Protocolo de Ouro Preto, em 1994, mas a abertura efetiva do arcabouço institucional do MERCOSUL aos órgãos de cunho essencialmente social apenas pôde ser observado com a mudança de governantes nos quatro países, o que possibilitou uma reorientação dos rumos da integração regional.

A integração política aparecia, então, como uma dentre a agenda de oportunidades (PIETRAFESA, 2009:27) para as várias plataformas de convergência regional a serem trabalhadas. "As eleições de Lula, no Brasil, em outubro de 2002, e de Néstor Kirchner

\footnotetext{
7 Dizia Lula, por ocasião de sua posse a $1^{\circ}$ de janeiro de 2003, “a grande prioridade da política externa durante o meu Governo será a construção de uma América do Sul politicamente estável, próspera e unida, com base em ideais democráticos e de justiça social. Para isso é essencial uma ação decidida de revitalização do Mercosul, enfraquecido pelas crises de cada um de seus membros e por visões muitas vezes estreitas e egoístas do significado da integração. O Mercosul, assim como a integração da América do Sul em seu conjunto, é sobretudo um projeto politico. Mas esse projeto repousa em alicerces econômico-comerciais que precisam ser urgentemente reparados e reforçados. Cuidaremos também das dimensões social, cultural e científicotecnológica do processo de integração. Estimularemos empreendimentos conjuntos e fomentaremos um vivo intercâmbio intelectual e artístico entre os países sul-americanos. Apoiaremos os arranjos institucionais necessários, para que possa florescer uma verdadeira identidade do Mercosul e da América do Sul" (LULA da SILVA:2003, grifos nossos).
} 
para Presidente da Argentina, em abril de 2003, dariam origem a uma conjunção de fatores favoráveis à "parlamentarização" do MERCOSUL" (DRUMMOND, 2005:317, aspas da autora). Foi então que, em uma reunião entre os presidentes do bloco em Buenos Aires, em outubro de 2003, se apresentou a intenção política do estabelecimento de um órgão de representação dos povos no âmbito da estrutura institucional do MERCOSUL ${ }^{8}$.

Articulou-se, a partir dali, uma série de ações no âmbito dos Estados-partes para fundar o Parlamento regional em futuro próximo. Por indicação do poder executivo brasileiro foi designado um grupo de consultores legislativos da Câmara e do Senado para dar suporte à elaboração do Protocolo Constitutivo do Parlamento do MERCOSUL (PCPM). Em 2005, o Parlasul foi criado em substituição a CPC, ficando regido pelo disposto no referido protocolo.

A Decisão do CMC 23/2005, que incorporou o PCPM à base documental do bloco dispõe sobre a importância de fortalecer o âmbito institucional de cooperação interparlamentar, para avançar nos objetivos previstos de harmonização das legislações nacionais nas áreas pertinentes e agilizar a incorporação aos respectivos ordenamentos jurídicos internos da normativa do MERCOSUL que requeira aprovação legislativa. Além disso, de acordo com o discurso dos presidentes dos quatro países ${ }^{9}$, o Parlasul absorveria a missão institucional de abrigar a semente de uma cidadania sul-americana e sua existência viria a conferir maior equilíbrio e legitimidade ao bloco. O Parlasul, assim, seria o órgão responsável pela representação dos cidadãos dos Estados do MERCOSUL.

A grande diferença do Parlasul em relação à CPC é a de que enquanto esta representava os países membros do MERCOSUL, e por isso mesmo as cadeiras no órgão eram distribuídas de forma paritária entre os países, o Parlamento viria a ser o órgão de representação do cidadão, motivo pelo qual, juntamente com os mecanismos necessários para a realização das eleições diretas, a questão da adequação das bancadas ao tamanho das populações se fizesse tão necessária quanto urgente, incluindo também a questão da representação no processo de institucionalização do órgão, que somente viria a iniciar suas atividades e a compor a base institucional do bloco a partir de 2007.

O Parlasul tem sua normativa orientada pelo disposto na Declaração Presidencial sobre o Compromisso Democrático no MERCOSUL, de 1996 e no Protocolo de Ushuaia

\footnotetext{
${ }^{8}$ É necessário mencionar que, nesse primeiro momento, Uruguai e Paraguai se posicionaram contrários ao estabelecimento de um Parlamento no MERCOSUL, alegando que, pelo critério da representação proporcionais às populações, ficariam em desvantagem em relação aos sócios maiores, Argentina e Brasil. Os dois países, no entanto, logo após, aderiram ao projeto.

${ }^{9}$ Nestor Kirchner, na Argentina; Lula da Silva, no Brasil; Tabaré Vasquez, no Uruguai e Nicanor Duarte, no Paraguai.
} 
sobre o Compromisso Democrático no MERCOSUL, a República da Bolívia e a República do Chile, assinado em 1998. A organização interna do órgão se fundamenta na normativa disposta no PCPM, e foi planejada de modo a possibilitar a absorção das demandas cidadãs dos Estados-parte, assim de forma que os grupos políticos articulados no Parlasul permitam a reunião de parlamentares segundo alianças de interesse ou a identificação partidária.

No tocante à atividade parlamentar, de acordo com o artigo 19 do PCPM, são atos do Parlamento a elaboração de Pareceres, Projetos de Normas, Anteprojetos de Normas, Declarações, Recomendações, Relatórios, Disposições, além de um relatório semestral sobre as condições de defesa e garantia dos direitos humanos nos países do bloco. Ficou acertado que a manutenção financeira do órgão seria por meio de financiamento público, com a contribuição de cada Estado-parte definida em função do Produto Interno Bruto, PIB, e dos orçamentos nacionais, à exceção da "primeira etapa de transição" ${ }^{10}$, cujo orçamento ficou constituído pela divisão em partes iguais entre os Estados-parte.

Com a missão de elaborar um projeto que viabilizasse a interação entre o Conselho do Mercado Comum e o Parlamento do MERCOSUL, em dezembro de 2008 por decisão do CMC, reunido em Salvador, Bahia, foi criado o Grupo de Alto Nível sobre Relação Institucional entre o CMC e o Parlasul - GANREL, a ser composto por representantes dos Estados Partes designados pelas Coordenações Nacionais do Grupo Mercado Comum, GMC (MERCOSUL/CMC/DEC. No 47/08).

A intenção de colaborar para o desenvolvimento de uma cidadania sul-americana, entretanto, somente apareceu de maneira expressa nos planos de ação dos documentos oficiais dois anos depois, quando a decisão do CMC 64/2010 acordava sobre a criação do Estatuto da cidadania do MERCOSUL. O Caput do documento afirma ser necessário "consolidar um conjunto de direitos fundamentais e benefícios em favor dos nacionais dos Estados Partes do MERCOSUL e estabelecer um Plano de Ação para a conformação progressiva de um Estatuto da Cidadania do MERCOSUL, com vistas a sua plena implementação no trigésimo aniversário da assinatura do Tratado de Assunção"11. (MERCOSUL/CMC/DEC. Nº 64/10).

10 O PCPM estabeleceu etapas de institucionalização do Parlasul, que diziam respeito, principalmente, aos prazos para que se realizassem as eleições diretas para o órgão no interior dos Estados-parte. Ver: PCPM, Montevidéu, Uruguai, 2003. In: MAZZUOLI, Valério de Oliveira (Org.). Coletânea de Direito Internacional. 6. ed. São Paulo: Revista dos Tribunais, 2008.

1126 de março de 2021. 
O Estatuto, por sua vez, se fundamenta em um conjunto de direitos fundamentais e benefícios para os nacionais dos Estados Partes, tendo como base os objetivos apresentados nos Tratados Fundamentais do MERCOSUL e na sua normativa derivada. Dessa forma, o documento estabelecia um plano de ação cujos eixos centrais eram: a) a implementação de uma política de livre circulação de pessoas na região; b) a igualdade de direitos e liberdades civis, sociais, culturais e econômicas para os nacionais dos Estados Partes do MERCOSUL e; c) a igualdade de condições para acesso ao trabalho, saúde e educação. (MERCOSUL/CMC/DEC. No 64/10, art. $2^{\circ}$ ).

O Plano de ação, a seu turno, estabelece onze temas de inflexão, tais como: circulação de pessoas, fronteiras, identificação, documentação e cooperação consular, trabalho e emprego, previdência social, educação, transporte, comunicações, defesa do consumidor e direitos políticos. Destaque-se este último elemento, o qual prevê o estabelecimento e a avaliação de metas para o avanço progressivo do estabelecimento de direitos políticos, "de acordo com as legislações nacionais que regulamentem seu exercício, em favor dos cidadãos de um dos Estados Partes do MERCOSUL que residam em outro Estado-parte de que não sejam nacionais, incluindo a possibilidade de eleger parlamentares do MERCOSUL". (MERCOSUL/CMC/DEC. No 64/10, art. $3^{\circ}$ ).

À revelia do previsto pelos cronogramas e acordos firmados para sua implementação, o Parlasul enfrenta entraves ao seu efetivo funcionamento devido, entre outros, ao fato de que quatro dos cinco países membros do bloco, incluindo o Brasil, à revelia do que previa seu Protocolo Constitutivo, PCPM, não terem ainda realizado suas eleições diretas. ${ }^{12}$ Diante da observação da curta trajetória do órgão, desde sua instituição em 2007, a despeito de sua incapacidade decisória, o que se observa é que o Parlasul trabalha no limite, como órgão de consultoria aos órgãos executivos do bloco e às respectivas casas legislativas nacionais, com quem se comunica principalmente por meio de anteprojetos e projetos de norma, declarações e pareceres (TAJRA, 2011, 2014; TAJRA; MARTINS, 2013).

\section{CONSIDERAÇÕES FINAIS: UM OLHAR SOBRE O PARLASUL}

O diálogo democrático se apresenta como alternativa válida para a solução pacífica de potenciais controvérsias entre os países vizinhos e a aproximação do cidadão do

\footnotetext{
12 As etapas de adaptação das bancadas de cada Estado-parte e a implementação das eleições diretas de cada um dos Estados membros, ainda que com dificuldade e adaptações, vêm sendo paulatinamente inseridas nas agendas eleitorais dos Estados envolvidos. Ao Brasil e à Argentina, mais populosos, cabe maior representatividade no órgão regional, enquanto o Uruguai e o Paraguai, ao fim das etapas de transição, passarão a ter bancadas menos representativas (FIER, 2008).
} 
processo de integração traz uma maior coesão ao processo, posto que lança as bases mais sólidas para a sua legitimidade. No entanto, o Parlasul, embora abra a possibilidade de participação para a sociedade civil e as eleições diretas estejam, mesmo que com dificuldades, prevista no calendário eleitoral não só do Brasil, como dos demais membros envolvidos ${ }^{13}$, enfrenta desafios à sua institucionalização.

No tocante à atividade do órgão, entre 2007 e 2010 o Parlasul apresentou uma produção em ascendente progressão (TAJRA, 2011). Conforme dados colhidos na website do Parlasul, durante esta primeira fase de atividades do órgão, foram elaborados seis Projetos de norma, dois Anteprojetos de norma, um Relatório, 68 Declarações, 103 Disposições e 55 Recomendações aos órgãos executivos e aos poderes executivo e legislativo dos respectivos Estados membros do bloco ${ }^{14}$.

Embora não tenha sido realizada uma análise de conteúdo aprofundada sobre a matéria de cada um dos atos lançados, é perceptível a preocupação constante para com a absorção das demandas trabalhistas (a possibilidade dos cidadãos dos Estados-partes participarem efetivamente através de petições e sugestões a serem levadas à pauta de discussões do Parlamento) e da estrutura de transportes, principalmente na tríplice fronteira (Brasil-Argentina-Paraguai), permitindo que se estabeleçam os parâmetros de escoamento da produção com o consequente fortalecimento do mercado regional.

No entanto, a possibilidade de exercício e o alcance dessa cidadania são postos em xeque diante da fragilidade institucional e da sua ausência de competências legislativas. A atividade parlamentar empreendida pelo órgão funciona no limite como indicativo para que os órgãos decisórios do bloco e dos Estados nacionais analisem sua possível absorção pelo arcabouço normativo do MERCOSUL. Por ora, as recomendações aos órgãos executivos do bloco apresentam-se como a única possibilidade de participação civil na elaboração normativa, fazendo com que os representantes, eleitos pelo voto direto, tornem-se de fato instrumento da vontade política dos povos sul-americanos.

\footnotetext{
13 Somente o Paraguai já realizou eleições diretas para Parlamentar do MERCOSUL. A presidente Cristina Kirchner promulgou, em janeiro de 2015, a lei que autoriza e regulamenta as eleições diretas para o Parlamento do MERCOSUL na Argentina. O pleito deve ocorrer juntamente com as eleições presidenciais do mesmo ano.

14 Fonte: Base de dados documentais do Parlamento do MERCOSUL. Disponível em: http://www.parlamentodelmercosur.org/parlasur/innovafront/actos_del_parlamento.jsp?site=1\&contentid =7229\&channel=parlasur. Acesso em: 31/Mar./2015. Não havia informações sobre a produção de Pareceres, Opinões (Dictamen) e Relatórios de Direitos Humanos. No mesmo período, foram solicitados ainda dois pedidos de relatório ao Parlasul.
} 
Cabe ainda mencionar que, do ponto de vista do Direito Internacional, embora seja o MERCOSUL dotado de personalidade jurídica internacional ${ }^{15}$, os acordos que versam sobre a cidadania até agora firmados em seu âmbito não se transformam em automática obrigação para os países signatários, necessitando estes de aprovação nas respectivas instâncias legislativas nacionais. Quando se trata do Parlasul, a ausência de capacidades decisórias contribuem ainda mais para relegar o órgão ao ostracismo dentro do processo de integração ${ }^{16}$.

Ademais, com exceção do Protocolo de Ushuaia ${ }^{17}$, que discorre essencialmente sobre a manutenção da democracia e do Estado de Direito, ainda não se efetivou na base institucional do MERCOSUL nenhum acordo de caráter vinculativo com relação à defesa dos direitos de cidadania em si, estes figuram, pois, como "declarações e compromissos sem poder vinculativo, que apenas espelham o pensamento que os países membros devem seguir" (BETHONICO, 2007:05). Essas iniciativas, porém, ainda que pertencendo ao espectro das intenções e dos compromissos não jurídicos, definem um prisma diante do qual são estabelecidos compromissos comuns para com a defesa dos Direitos Humanos e da Cidadania na região.

\section{REFERÊNCIAS BIBLIOGRAFÁCIAS}

AZAmbUjA, M. C. de. O reordenamento Sarney-Alfonsín. In: A América do Sul e a Integração Regional. Brasília: FUNAG, 2011. p. 79-83.

BETHONICO, C. C. de O.: Os direitos humanos no MERCOSUL. In: Revista de Direitos Fundamentais e Democracia, Curitiba, v. 2, n. 2, Jul./Dez./2007. Disponível em: $<$ http://revistaeletronicardfd.unibrasil.com.br/index.php/rdfd/article/view/142>. Acesso: 10 out. 2013.

BUENO, C.: O Brasil e o integracionismo: do ABC de Rio Branco à operação panamericana. In: A América do Sul e a Integração Regional. Brasília: FUNAG, 2011, pp. 43-62. ; CERVO, A: Histórica da politica exterior do Brasil. Brasília: Editora UnB, 2011.

\footnotetext{
15 Conferida pelo Protocolo de Ouro Preto, assinado em 1994. Além da personalidade jurídica, o documento estabeleceu as bases atuais da estrutura institucional do bloco.

${ }^{16}$ Somente as Decisões do Conselho do Mercado Comum, CMC, as Resoluções do Grupo Mercado Comum, GMC, e as Diretrizes da Comissão de Comércio do MERCOSUL, CCM, constituem fontes jurídicas às quais os Estados partes do bloco, da perspectiva legal, obrigam-se a executar. Leia-se, a submeter ao crivo do poder legislativo.

17 Protocolo de Ushuaia sobre o compromisso democrático no MERCOSUL, na República da Bolívia e na República do Chile, assinado em 1998.
} 
DORATIOTO, F. F. M.: Formação dos Estados nacionais e expansão do capitalismo no século XIX. In: CERVO, A.; RAPOPORT, M. (Ogs.): História do Cone Sul. Rio de Janeiro: Revan; Brasília: Editora da Universidade de Brasília, 1998, pp. 168-237.

DRUMMOND, M. C.: A democracia desconstruida. O déficit democrático nas relações internacionais e os parlamentos da integração. Brasília: Instituto de Ciências Humanas, Departamento de História, Universidade de Brasília, 2005.

FERNANDES, T. C.: Entre Bolívar e Monroe - o Brasil nas relações interamericanas. In: SALAZAR, L. S.; LORENZO, T. G.: Las relaciones interamericanas - continuidades y cambios. Buenos Aires: Consejo Latinoamericano de Ciencias Sociales - CLACSO, 2008. p. 213-238. Campus virtual de CLACSO. Disponível em: $<$ http://bibliotecavirtual.clacso.org.ar/ar/libros/campus/salazar/08coel.pdf>. Acesso em: 28 jan. 2014.

FIER, F. [Deputado Federal Dr. Rosinha]: Parlamento do MERCOSUL: Identidade Comum e Cidadania. Parlamento do MERCOSUL, 2008. Disponível em: <http://www.senado.gov.br/evmMERCOSUL//publico/setores/000/33/noticias/2008/ 8/358/Artigo $\% 20$ Rosinha $\% 20$ -

$\% 20 \mathrm{O} \% 20$ Parlamento $\% 20 \mathrm{do} \% 20$ MERCOSUL $\% 20 \mathrm{e} \% 20$ cidadania.pdf $>$. Acesso em: $17 /$ mar./2012.

LULA da SILVA, L. I.: Discurso de posse do Presidente da República. Brasília: Secretaria de Imprensa e Divulgação da Presidência da República, 2003.

MERCOSUL: Conselho do Mercado Comum. Decreto n ${ }^{\circ}$ 47, de 15 de dezembro de 2008. Grupo de Alto Nivel sobre a Relação Institucional entre o Conselbo do Mercado Comum e o Parlamento do MERCOSUL. Salvador, BA, 15 de dezembro de 2008. Disponível em: <wnw.mercosur.int/.../Decisiones/.../DEC_047-2008_PT_FERR_Criasao\%2...>.

: Protocolo Constitutivo do Parlamento do MERCOSUL. Montevidéu, Uruguai, 2003. In: MAZZUOLI, Valério de Oliveira (Org.). Coletânea de Direito Internacional. 6. ed. São Paulo: Revista dos Tribunais, 2008.

: Regimento Interno do Parlamento do MERCOSUL. Montevidéu, Uruguai: Departamento de documentación y Normativa - Secretaria Parlamentaria, 2003. Disponível em: <http://www.parlamentodelmercosur.org/innovaportal/v/4296/1/secretaria/\%20 Documentos_de_refer\%C3\%AAncia.html?seccion=2>. Acesso em: 15 abr. 2013.

: Protocolo de Ushuaia sobre o Compromisso Democrático no MERCOSUL, República da Bolívia e a República do Chile. Ushuaia, Bolívia, 1998. In: MAZZUOLI, V. de O. (Org.): Coletânea de Direito Internacional. 6. ed. São Paulo: Revista dos Tribunais, 2008.

: Declaração presidencial sobre compromisso democrático no MERCOSUL. Brasília, 1996. In: MAZZUOLI, V. de O. (Org.): Coletânea de Direito Internacional. 6. ed. São Paulo: Revista dos Tribunais, 2008. 
: Protocolo Adicional ao Tratado de Assunção sobre a estrutura institucional do MERCOSUL - Protocolo de Ouro Preto. Ouro Preto, MG, 1994. In: MAZZUOLI, V. de O. (Org.): Coletânea de Direito Internacional. 6. ed. São Paulo: Revista dos Tribunais, 2008.

: Tratado de Assunção. Assunção, Paraguai, 1991. In: MAZZUOLI, V. de O. (Org.): Coletânea de Direito Internacional. 6. ed. São Paulo: Revista dos Tribunais, 2008.

MONIZ BANDEIRA, L. A. de V.: A relações regionais no Cone Sul: iniciativas de integração. In: CERVO, A.; RAPOPORT, M. (Ogs.): História do Cone Sul. Rio de Janeiro: Revan; Brasília: Editora da Universidade de Brasília, 1998, pp. 290-333.

RIGGIROZZI, P.: Hacia un regionalismo post-neoliberal en América Latina: reforma o ruptura? In MARTINS, M. D.; GALLY, R. E. (Orgs.): Multilateralismo e reações sul-americanas. Fortaleza, EdUECE, 2011, pp. 283-312.

PIETRAFESA, P. A.: A construção de uma nova instituição parlamentar no Cone Sul: O Parlamento do MERCOSUL. Brasília: Instituto de Ciências Sociais, Centro de Pesquisa e PósGraduação sobre as Américas (CEPPAC), 2009.

SANTOS, L. C. V. G. dos: O evangelho do Barão: Rio Branco e a identidade brasileira. São Paulo: Editora da UNESP, 2012.

: A América do Sul no discurso diplomático brasileiro. Revista Brasileira de Política Internacional, Brasília, v. 48, n. 2, p. 185-204, jul./dez. 2005.

: O Brasil entre a América e a Europa: o império e o interamericanismo (do Congresso do Panamá à Conferência de W ashington). São Paulo: Editora da UNESP, 2004.

TAJRA, J. L. F.: A participação dos povos na integração sul-americana: O papel do Parlamento do MERCOSUL. Fortaleza: Universidade Federal do Ceará, 2011, monografia de graduação.

: Integração Sul-Americana: Uma incursão ao conceito de cidadania no âmbito do Parlamento do MERCOSUL. Fortaleza: Universidade Estadual do Ceará, 2014, dissertação de mestrado.

; MARTINS, M. D.: A contribuição do Parlamento do MERCOSUL para a integração sul-americana - os atributos da cidadania regional. XXIX Congresso Latino-Americano de Sociologia. Santiago: FLACSO, ALAS, 2013.

VIDIGAL, C. E.: A Integração Sul-Americana como um projeto Brasileiro: de Uruguaiana às Malvinas. In: A América do Sul e a Integração Regional. Brasília: FUNAG, 2011. p. 63-77. 